\title{
Individual-level predictors of cessation behaviours among participants in the International Tobacco Control (ITC) Four Country Survey
}

\author{
A Hyland, R Borland, Q Li, H-H Yong, A McNeill, G T Fong, R J O'Connor, K M Cummings
}

Tobacco Control 2006;15(Suppl III):iii83-iii94. doi: 10.1136/tc.2005.013516

Background: The International Tobacco Control (ITC) Four Country Survey (ITC-4) is a prospective cohort study designed to evaluate the psychosocial and behavioural impact of national-level tobacco control policies enacted in the Australia, Canada, the UK, and the USA. Wave 1 of ITC-4 survey was conducted between October 2002 and December 2002. Wave 2 survey was conducted between May 2003 and August 2003.

See end of article for authors' affiliations Objective: To test for individual-level predictors of smoking cessation behaviours (that is, quit attempts and smoking cessation) among cigarette smokers in the ITC Four Country Study measured between Wave 1 and Wave 2. This set of predictors will serve as the base for evaluating the added effect of tobacco control policies and other factors.

Correspondence to: K Michael Cummings, $\mathrm{PhD}, \mathrm{MPH}$, Roswell Park Cancer Institute, Department of Health Behavior, Elm and Carlon Streets, Buffalo, NY 14263, USA; michael. cummings@roswellpark. org

Methods: Respondents included in this study are 6682 adult current smokers in the Wave 1 main survey who completed the Wave 2 follow-up (1665 were in Canada, 1329 were in the USA, 1837 were in the UK and 1851 were in Australia).

Results: Factors predictive of making a quit attempt included intention to quit, making a quit attempt in the previous year, longer duration of past quit attempts, less nicotine dependence, more negative attitudes about smoking, and younger age. Lower levels of nicotine dependence were the main factor that predicted future cessation among those that made a quit attempt.

Conclusion: Intention to quit and other cognitive variables were associated with quit attempts, but not cessation. Behavioural variables related to task difficulty, including measures of dependence, predicted

Received 15 July 2005 Accepted 22 March 2006 both making attempts and their success. Predictors of making quit attempts and cessation were similar for each of the four countries, but there were some differences in predictors of success.

$\mathrm{T}$ rends in tobacco use behaviours vary in different regions of the world. ${ }^{1}$ In the four large developed nations that are the focus of this paper and where on some level each society has taken on the tobacco problem by at least educating the public about the risks and implementing other tobacco control measures, the smoking prevalence rates have decreased over time. In the United States, smoking prevalence among adults ( 18 years or older) decreased from $33.2 \%$ in 1980 to $22.8 \%$ in $2001 .^{2}$ In Canada, smoking prevalence dropped from $35.1 \%$ in 1985 to $21.7 \%$ in $2001 .^{3}$ Australia also experienced a continual decline in the prevalence of smoking from $35 \%$ in 1980 to $23 \%$ in $2001 .{ }^{4}$ Smoking rates in the United Kingdom have declined from $39 \%$ in 1980 to $27 \%$ in $2001 .^{5}$

In contrast, different patterns of smoking exist in many lower income countries where smoking rates are high, often, but not always, with higher rates among males compared with females. ${ }^{67}$ Given the difference between countries and the importance of smoking cessation, studies are needed to compare and contrast the predictors of quitting in these countries.

The central aim of this paper is to test a model of proximal individual level predictors of quitting that was built into the International Tobacco Control (ITC) Four Country Survey (ITC-4) and to test whether this model applies in all four countries studied. The essence of the model is a combination of expectancy-value models ${ }^{8}$ and behavioural predictors. Classical expectancy value theories such as the theory of planned behaviour ${ }^{9}$ have most, if not all, cognitive predictors mediated through intentions, while social cognitive theory ${ }^{10}$ does not incorporate intentions. However, in concert with the empirical evidence that shows that variables that predict the intention to quit include stronger desire to quit and knowledge and perceptions of smoking, ${ }^{11-13}$ we postulate that at least some cognitive variables will predict quitting independent of intention. This is because smoking is a difficult behaviour to change, and most current smokers have tried and thus failed. In addition, behavioural variables are added to these measures because past behaviour is a strong predictor of future behaviour.

Attempting to quit smoking has two major components, actually initiating an attempt and maintaining cessation once quit. These are two quite distinct tasks, so we should not expect the predictors to be equivalent. ${ }^{14}{ }^{15}$ For example, selfefficacy is more constantly predictive of success than it is of making attempts. ${ }^{14} 16$ Other studies examining factors predicting making a quit attempt found they include motivation to quit and past quit attempts, ${ }^{14} 1718$ indicators of nicotine dependence, ${ }^{17-20}$ concern for health effects caused by smoking, ${ }^{15}$ and demographic factors such as younger age, white race and higher education. ${ }^{18}{ }^{20-22}$

Factors that have been associated with quitting success include level of nicotine dependence, ${ }^{14-18} 23-34$ self-efficacy, ${ }^{14}{ }^{16}$ demographics including older age, male sex, white race, and higher socioeconomic status, ${ }^{14} 21232530333536$ stronger desire to quit, ${ }^{12} 1421232432$ and longer length of past quit attempt. ${ }^{35} 37$

There are several studies that examine basic intrinsic predictors of cessation, ${ }^{14}{ }^{15} 23-2729$ although few utilise nationally representative samples of smokers (or even samples that

Abbreviations: CPD, cigarettes per day; HSI, heaviness of smoking index; ITC-4, International Tobacco Control Four Country Survey 
are drawn from non-help-seeking populations) and even fewer that compare predictors of cessation across countries. Comparing differences in predictors of tobacco use behaviours across countries offers the opportunity to gauge the extent to which differences in tobacco control environments and socio-cultural factors may contribute to varying trends in tobacco use behaviours in contrast to individual-level or intrinsic factors such as nicotine dependence, and also to explore the universality of some influences.

The central goal of the ITC Project is to understand the mediational pathways by which policies impact on cessation behaviour. ${ }^{38}$ The set of predictors identified here will be used in other studies on the ITC dataset for some analyses, whereas more detailed mediational models may be used in others, to attempt to understand how and why policies influence behaviours.

\section{METHODS}

\section{Data source}

Data analysed in this paper came from the first two waves of the ITC-4 Survey. A detailed description of ITC-4 Survey can be found elsewhere. ${ }^{38-40}$ Briefly, the ITC-4 Survey is a prospective cohort study designed to evaluate the psychosocial and behavioural impact of key national-level tobacco control policies enacted in Australia, Canada, the UK, and the USA. All aspects of the study protocol and survey measures are standardised across the four countries.

Wave 1 of the ITC-4 Survey was conducted between October 2002 and December 2002. The Wave 1 survey could be divided into two stages. During the recruitment stage, random digit dialling was used to recruit current smokers aged 18 years or older within strata defined by geographic region and community size in the four countries. Qualifying respondents were asked to participate in a 35-minute survey (the main survey) and the subsequent follow-up surveys. The main survey was conducted typically one week after the recruitment. Study participants were asked questions in several policy domains. A total number of 9058 respondents completed the Wave 1 main survey, which included 2214 in Canada, 2401 in the UK, 2138 in the USA, and 2305 in Australia. Among these 8915 respondents reported that they were still smoking at the time of the main interview.

The Wave 2 follow-up survey was conducted between May 2003 and August 2003 among respondents who completed the Wave 1 survey. A total number of 6754 respondents completed the follow-up survey (follow-up rate $75 \%$ ). Respondents included in this study are current smokers in Wave 1 main survey who completed Wave 2 follow-up and responded to at least $80 \%$ of the survey. A total number of 6682 respondents met these criteria. Among them, 1665 were in Canada, 1329 were in the USA, 1837 were in the UK, and 1851 were in Australia. The follow-up completion rate in each country was: $75 \%$ in Canada, $63 \%$ in the USA, $78 \%$ in the UK, and $81 \%$ in Australia.

\section{Outcome measures}

The outcomes assessed in this study were: (1) quit attempts; (2) quitting among those who made a quit attempt; and (3) quitting among the entire baseline sample. All data are based on self-report and are not subject to biochemical validation. At Wave 1, all respondents were current smokers defined as having smoked at least 100 cigarettes in their lifetime and currently smoking on at least a monthly basis. Definitions of each outcome are given below.

A subject was defined as having made a quit attempt if they responded affirmatively to the question, "Have you made any attempts to stop smoking since we last talked with you in [month of last interview]?"
Successful smoking cessation was defined as a current smoker at Wave 1 who now reports not smoking at all or smoking less than once per month in Wave 2 based on the following questions, "The last time we spoke to you in [month] you said that you smoked [daily/weekly/monthly]. Do you still smoke [daily/weekly/monthly]?" Those who indicated otherwise were then asked if they are now smoking daily, less than daily but at least once a week, less than once a week but at least once a month, or less than once per month. Those who reported they smoked less than once per month were defined as quitters in Wave 2. Two models are constructed using this outcome. The first is restricted only to those who made a quit attempt, and the second model includes all Wave 1 smokers.

\section{Core predictor variables}

The following core set of predictor variables is examined in this study.

\section{Sociodemographic variables}

- Country (Australia, Canada, UK, and USA)

- Age at recruitment, in years (18-24, 25-39, 40-54, 55 and older)

- Sex (female, male)

- Education (low, moderate, high): The education questions differed among the four countries due to different educational systems. For each country, low levels of education were considered to be: completed high school or less in Canada, USA, and Australia, or secondary/ vocational 3 or less in the UK; moderate levels were considered to be: community college/trade/technical school/some university (no degree) in Canada and the USA, college/university (no degree) in the UK, or technical/trade/some university (no degree) in Australia; and high levels were those who completed university or postgraduate in all countries.

- Income (low, moderate, high): In this study, those whose annual household income was less than \$30000 (or $£ 30000$ in the UK) were coded as "low income", those between $\$ 30000$ and $\$ 59999$ (or $£ 30000$ and $£ 44999$ in the UK) were coded as "moderate income", and those equal to or greater than $\$ 60000$ (or $£ 45000$ in the UK) were coded as "high income". Those who refused to provide their income were given a valid code for "refused".

- Identified minority group: We used the primary means of identifying minorities used in official surveys conducted in each nation, and this was racial/ethnic group (USA, Canada, and UK) and language other than English spoken at home (Australia). Respondents were classified as being in the majority group if they were white (USA, Canada, UK) or spoke English in the home (Australia) and were defined in the identified minority group otherwise.

\section{Beliefs about quitting variables}

- Intention to quit (in next month, in next 6 months, beyond 6 months, not planning to quit): This variable comes from the question "Are you planning to quit smoking (in next month, in next 6 months, beyond 6 months, not planning to quit)?"

- Self-efficacy of quitting: At Wave 1 of the ITC-4 Survey, current smokers were asked, "If you decided to give up smoking completely in the next 6 months, how sure are you that you would succeed?" Categories of the answer include: not at all sure, slightly sure, moderately sure, very sure, and extremely sure. The variable was coded as a continuous measure from 1 (weak) to 5 (strong). 


\section{Motivational variables}

- Outcome expectancy of quitting: At baseline survey, smokers were asked, "How much do you think you would benefit from health and other gains if you were to quit smoking permanently in the next 6 months?" Categories of the answer include: not at all, slightly, moderately, very much, and extremely. The variable was coded as a continuous measure from 1 (weak) to 5 (strong).

- Worries about health and quality of life: This variable was created based on smokers' responses to two questions at baseline: (1) "How worried are you, if at all, that smoking will lower your quality of life in the future?" (2) "How worried are you, if at all, that smoking will damage your health in the future?" Categories of the answers include: not at all worried, a little worried, moderately worried, very worried. Each variable was coded as a continuous measure from 1 (weak) to 4 (strong) and the average of the two measures was used in analyses.

- Favourable attitudes about smoking: This variable was created based on smokers' response to the following two statements: (1) "You enjoy smoking too much to give it


variable was coded as a continuous measure from 1 (weak) to 5 (strong) and the average of the two measures is used in analyses.

- Overall attitude about smoking: At baseline, smokers were asked: "What is your overall opinion of smoking?" The variable was coded into a three-category variable: positive or neutral (very positive, positive, or neither positive nor negative), negative, or very negative.

\section{Past quitting history variables}

- Tried to quit within last year (yes, no)

- Longest time off smoking (never, 1 week or less, between 1 week and 6 months, 6 months or more)

\section{Nicotine dependence variables}

- Heaviness of smoking index (HSI): The heaviness of smoking index was created as the sum of two categorical measures: number of cigarettes smoked per day (coded: 0 : 0-10 cigarettes per day (CPD), 1: 11-20 CPD, 2: 21-30 CPD, 3: $31+\mathrm{CPD}$ ), and time to first cigarette (coded: 0 : 61+min, 1: 31-60 min, 2: 6-30 min, 3: 5 min or less). Values for this variable range from 0 to 6 . This index is positively associated with nicotine dependence. ${ }^{41}$

- Baseline smoking frequency (daily smoker, less than daily smoker)

\section{Statistical analysis}

Multivariate logistic regression was used to examine the association between cessation outcomes and all intrinsic predictor variables entered into the model such that the relative risks presented for a given variable are adjusted for all other covariates in the model. The interactions between country and other independent variables were also examined. Backward (Wald) stepwise selection was used to choose significant interaction terms at the $5 \%$ level after entering all the main effects in the model.

\section{RESULTS}

Thompson et al present the characteristics of the ITC-4 sample in another paper in this issue. ${ }^{39} 40$

Table 1 shows the predictors of making serious quit attempts between wave 1 and 2 surveys among baseline smokers. Overall, $36 \%$ of the baseline smokers made quit attempts in the 8-10 months between Waves 1 and 2. After adjusting for covariates, quit attempt rates were higher, relative to other categories in each variable mentioned: among those who lived in Canada, were 18-24 years of age, intended to quit sooner, had tried to quit in the past year, had a previous attempt lasting for six months or longer, had low levels of nicotine dependence, smoked less than daily, had very negative opinions about smoking, were more worried about health effects of smoking, and perceived few benefits from smoking. No two-way interactions between country and predictor variables were significant at the $5 \%$ level.

Table 2 shows the predictors of successful quitting among 2426 smokers who made a quit attempt between Waves 1 and 2. Overall, $25 \%$ of those who made a quit attempt were still stopped at Wave 2. While cessation rates were highest in the UK (29\%) followed by Canada (24\%), Australia (23\%), and the USA $(22 \%)$, these differences were not significant in multivariate analysis. Overall, those with lower levels of nicotine dependence (those with lower HSI or smoked less than daily) were more likely to quit. Those with a longest past quit attempt of less than a week were less likely to quit successfully compared to those without any past quit attempts. Those who expected smaller health and other gains from quitting were more likely to quit successfully while a borderline association was observed for self-efficacy. Other factors were not significant in the overall model, although some predictors were significant in country-specific analyses. The reduced sample size resulting from the focus on only those who made a quit attempt might partly explain the general lack of significant factors. Significant interactions were found between the country variable and the following three independent variables $(p<0.05)$ : (1) heaviness of smoking index (generally significant in the USA, Canada, and Australia but not significant in the UK); (2) favourable attitudes about smoking (a significant predictor of relapse in Canada, but non-significantly positive in the other three countries); and (3) self-efficacy (a non-significant association with successful cessation was found in the UK and Australia compared to no effect in Canada and the USA).

Table 3 shows the predictors of quitting among 6682 smokers who completed both Waves 1 and 2 surveys, regardless of whether they made a quit attempt or not. Overall, $9 \%$ of the baseline sample of smokers had quit by Wave 2 with no statistical differences found between countries. Significant predictors of increased cessation in multivariate analysis included those who showed less nicotine dependence, smoked in a less than daily basis, had greater intention to quit, tried to quit within last year, and had past history of a quit attempt lasting six months or longer. Those who had higher expectations of health and other benefits of quitting and were aged 40-54 had lower rates of cessation. One significant interaction was found between country and ever tried to quit within last year, with the association not being present in Australia but significant in the other three countries.

We summarise the findings in fig 1 , where the unexpected associations are in italics and the expected ones bolded.

\section{DISCUSSION}

There are four main findings from this study: (1) nicotine dependence was the most consistent variable associated with quit attempts and cessation across all four countries; (2) motivational factors including intention to quit and a history of past quit attempts were strongly associated with making a quit attempt, but not independently associated with succeeding in that attempt; (3) overall quit rates were a function of the percentage of smokers making a quit attempt and the success rate among those who tried to quit; and (4) there 


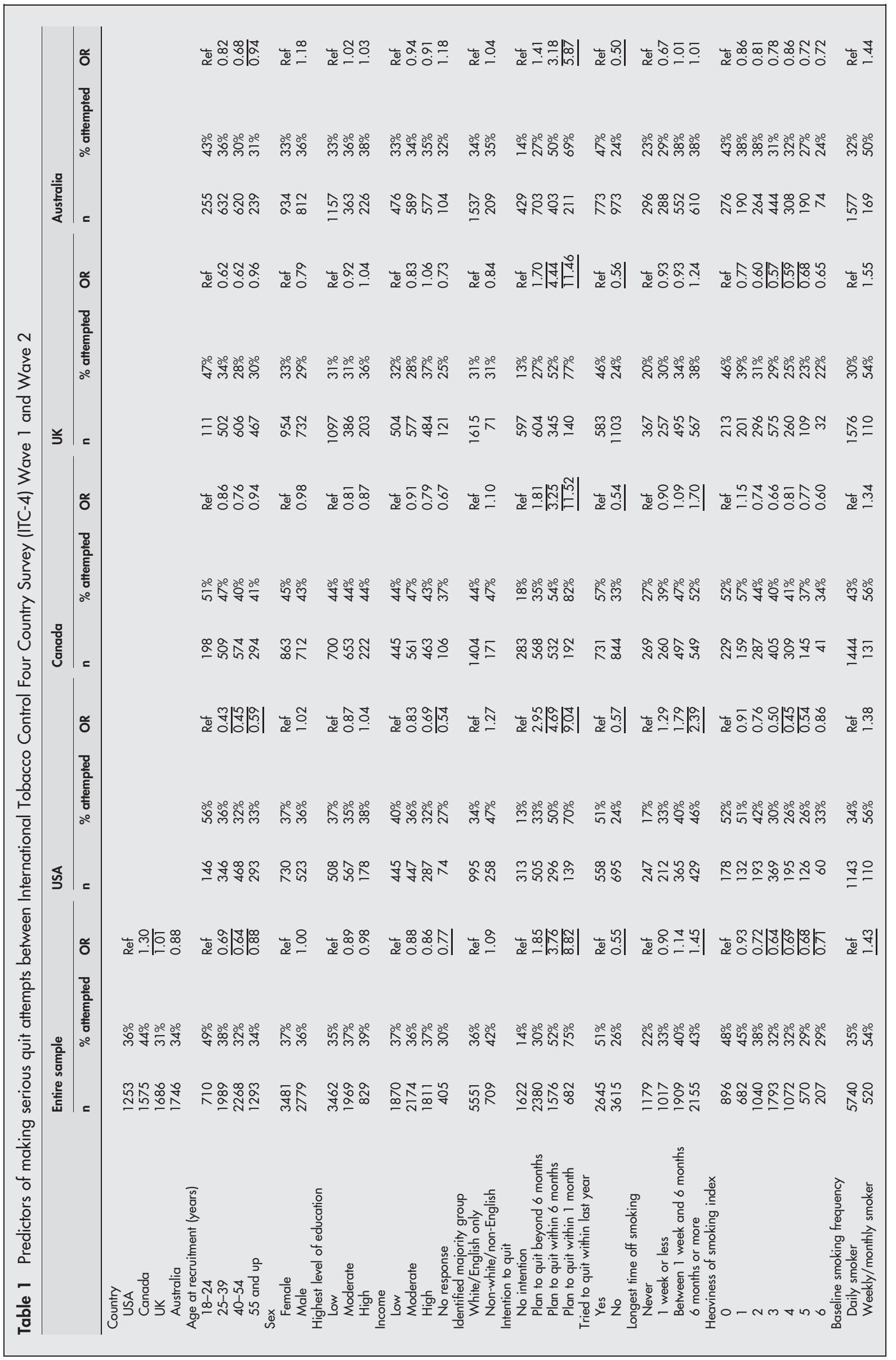




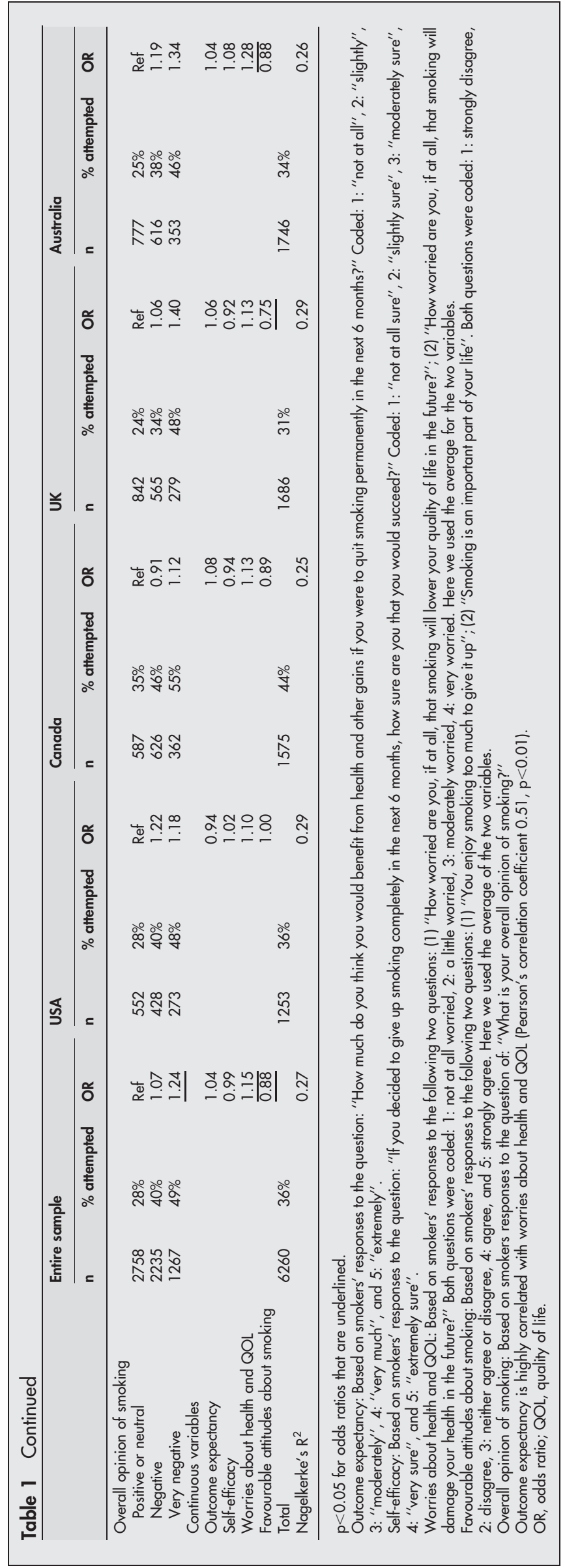




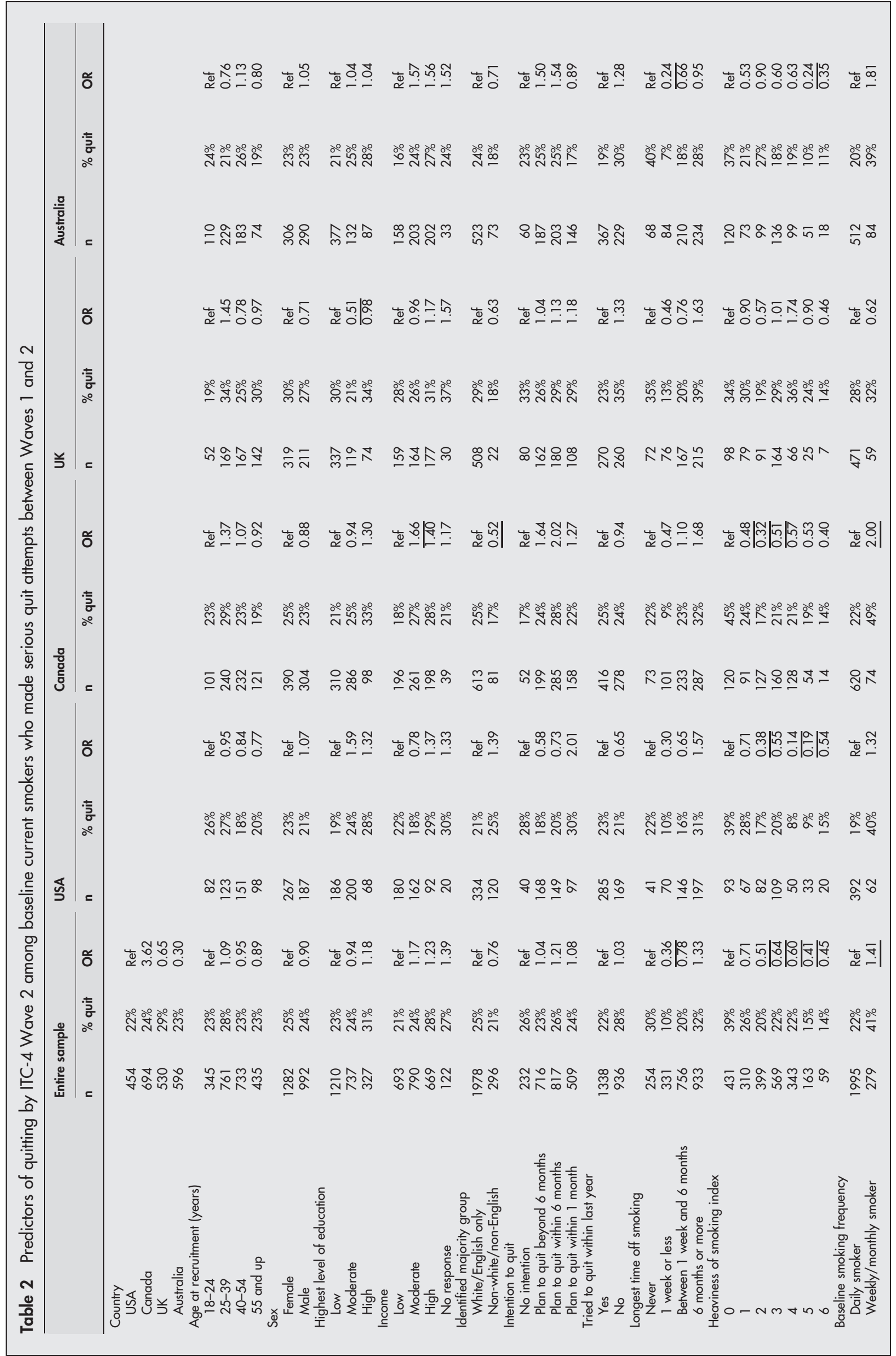




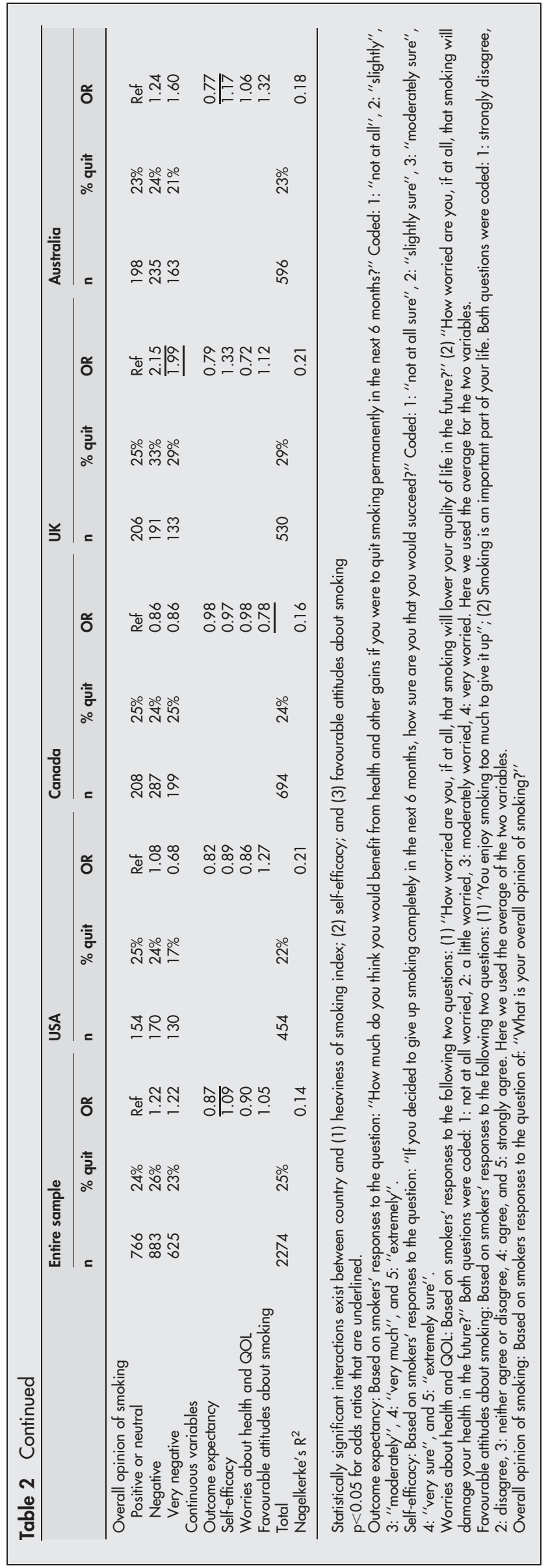

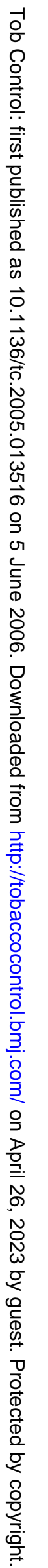




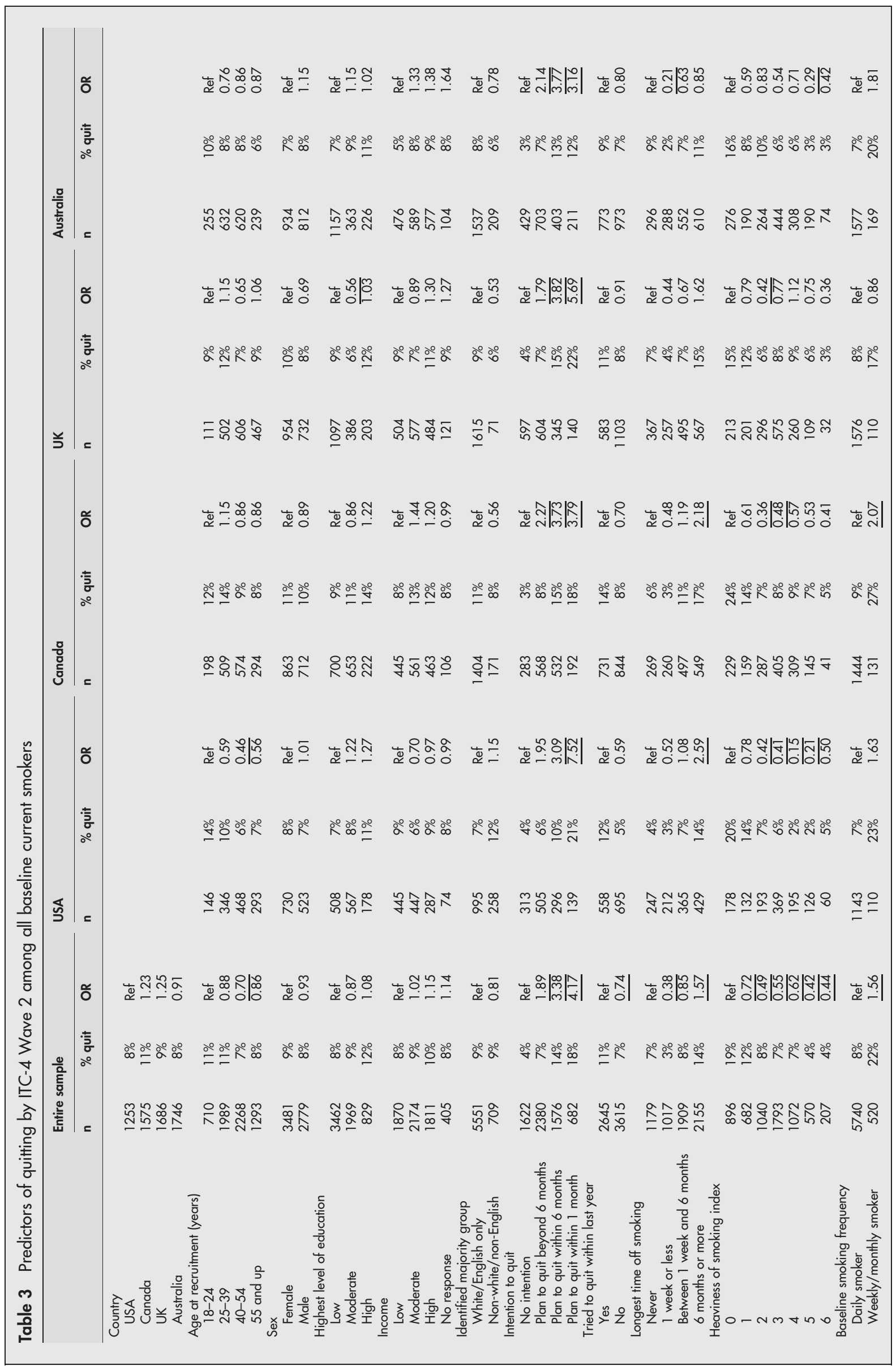




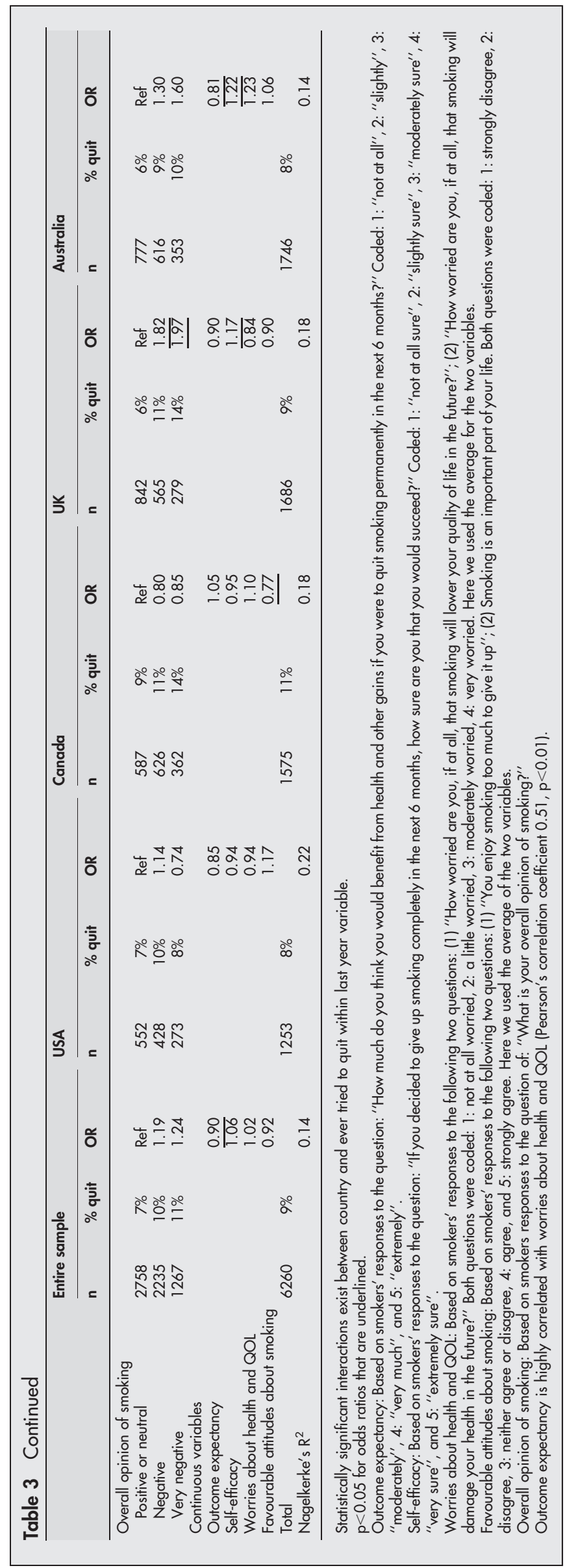

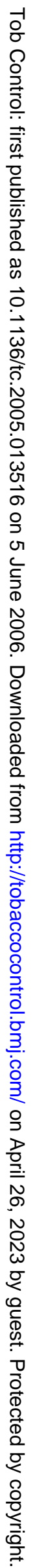




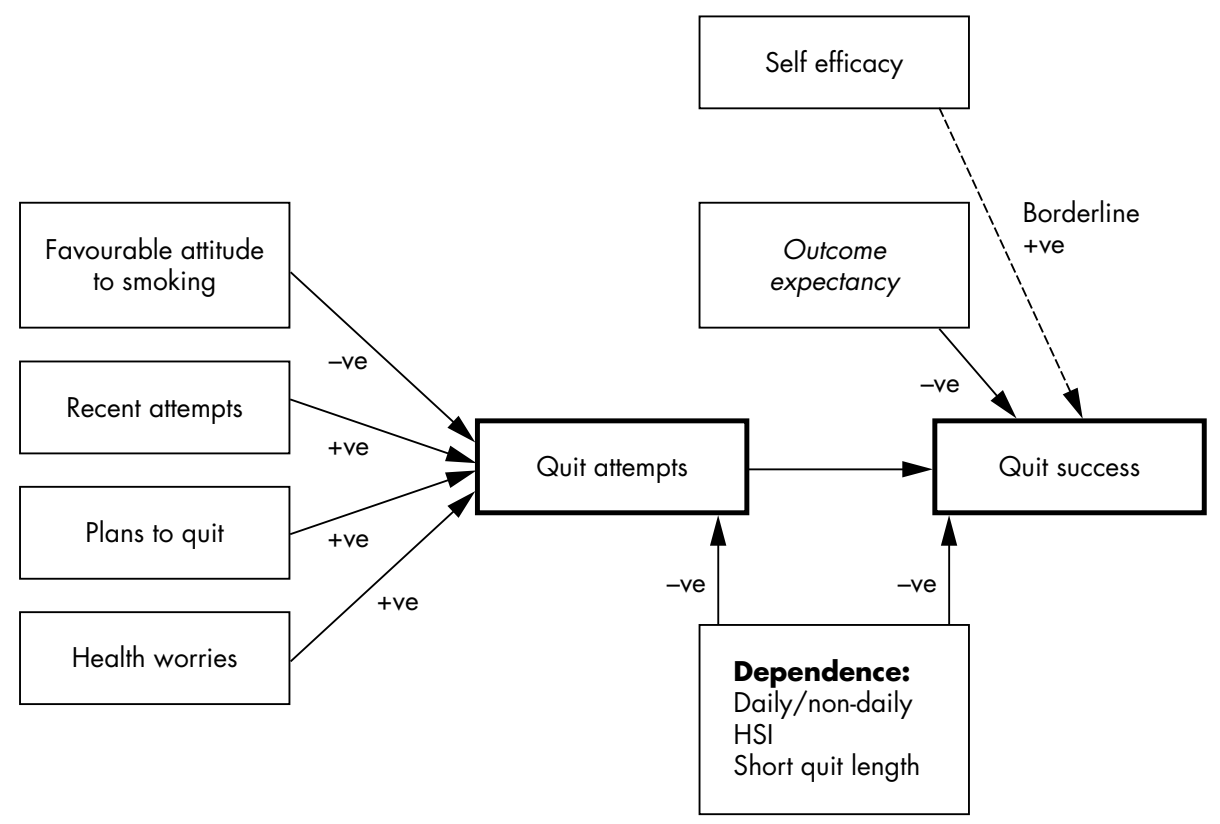

Figure 1 Schematic model of the main predictors of making quit attempts and of the success of those attempts. HSI, heaviness of smoking index; +ve, significant increase between the two variables connected by the given line; - ve, significant decrease between the two variables connected by the given line; younger age and living in Canada are predictive for making quit attempts; sex, race, education, and income are not predictive for making quit attempts in this study; country, age, sex, race, education and income are not predictive for successful quitting among smokers who made serious quit attempts in this study.

were no significant differences in predictors of quit attempts but some differences in success of attempts across countries.

Indicators of motivation to quit are the strongest predictors of making a serious quit attempt, although indicators of nicotine dependence also add predictive value. These findings are consistent with previous studies. ${ }^{14} 19$ Previous research has shown demographic characteristics are also associated with making a serious quit attempt ${ }^{21}{ }^{22}$; however, in the present study sex and education were not associated with making a serious quit attempt. This may be because we were better able to control for more direct correlates, such as level of dependence, which are correlated with the demographic variables.

The main finding that nicotine dependence is strongly associated with quit rates is also consistent with previous literature. ${ }^{14-18}{ }^{23-34}$ Looking in more detail at the findings, it is clear that non-daily smokers and those who scored zero on the HSI were particularly likely to quit. The lack of linearity in the relationship between HSI and quit attempts suggests a threshold effect where quitting is much more likely at low levels of nicotine dependence. This suggests that interventions that reduce consumption to these very low levels may indirectly boost future cessation rates. ${ }^{42-44}$ An alternative explanation is that low HSI scores are a marker for an environment that discourages smoking and encourages quitting.

Also related to dependence is the duration of past quit attempts. The finding that short previous past attempts (less than a week) was associated with reduced success while longer attempts (six months or more) was associated with increased success compared with no previous attempts, is of note. It suggests that quick failures of quit attempts may have a negative effect on subsequent attempts, while longer attempts may be advantageous. This raises the question of whether we should try to encourage smokers to make a quit attempt that lasts as long as they can manage to test their readiness to quit, regardless of the perceived likelihood of success on that quit attempt. We think it premature to make such suggestions on the basis of this study alone, but encourage research around this issue.

The findings suggest that, with the possible exception of self-efficacy, the variables used in expectancy-value based models of behaviour change apply primarily to the making of the attempt to change rather than to the success of attempts. For hard-to-change behaviours like smoking, different models are required for understanding success than for understanding efforts to try to change. Measures of dependence were the only measures in this study that predicted both quit attempts and quitting, which suggests that interventions that focus on dependence are preferable to interventions that only focus on expectancy-based variables.

Some other studies have found demographic differences between quitters and continued smokers; however, we found few such differences in this study. For example, we found no sex differences for quitting in the present study; however, other large population-based studies have found lower cessation rates among females. ${ }^{25}$ Other studies have reported that older age was another strong predictor of successful cessation $^{2123}$ 29; however, age was not associated with quitting independent of the likelihood of making a quit attempt in the present study. Some other studies show race/ ethnicity is associated with cessation, ${ }^{29}{ }^{45}$ but race/ethnicity was also unrelated to cessation in the present study after adjusting for other factors. It should also be noted that the quit rates in this study are higher than those presented in some other studies. This is likely attributed to the difference in the definition of cessation, which is the current self report of smoking not at all or on less than a monthly basis.

One surprising factor was the general lack of an association between nicotine dependence and quit success of those who made a quit attempt in the UK, particularly in the mid-range levels of the HSI. We do not have a simple explanation for this observation. We hope that future data from this project may provide additional insight.

The finding that those with the highest expectancies that quitting would enhance their health relapsed at a greater rate 
is interesting. It could be that some smokers overestimate the short-term health improvements from smoking and are more prone to relapse when the gains are measured in perceived small, continual improvements over many months and years. Alternatively, it could be that good reasons for maintaining motivation to remain smoke-free after quitting are reasons that stress the realistic immediate short-term benefits of quitting rather than more distant, long-term reasons (that is, long-term health) that are difficult for a person to quantify or unrealistic expectations. If this is so, it would suggest the need to articulate more carefully alternatives for the perceived benefits smokers think they get from smoking, and thus which they think they forfeit when they quit. Dijksta et al found evidence that beliefs of this kind do predict relapse. ${ }^{16}$ However, in our study beliefs about the benefits of quitting did not have direct predictive effects. Future work is needed to identify smokers who might derive more benefit from behavioural interventions that stress positive versus negative reasons for quitting smoking.

Another interesting observation is the finding in Canada that having a strongly negative attitude to smoking was associated with relapse, something that was not the case in the other three countries. Again we have no ready explanation for this, and will be looking closely in subsequent waves to see if it persists and to try to find explanations if it does.

The overall cessation rate in the baseline sample is a function of both the prevalence of respondents that make a quit attempt and the success rate among those who try to quit. While overall quit rates were not statistically different between countries, the highest overall quit rates were observed in Canada where the fraction of smokers trying to quit was much higher although the rate of success among those who tried was comparable to the lowest country. This is in contrast to the UK, which had the second highest overall cessation rate, where the lowest rate of making a quit attempt was observed but those who did try to quit had the highest success rate. Taken together, tobacco control interventions that increase the fraction of smokers making a quitting attempt as well as their likelihood of success are effective measures for increasing cessation in the population. $^{15}$

Another noteworthy point to address is the similarity of findings across the four countries. Country specific analysis for predictors of quitting and quit attempts among the entire sample only reveals one significant two-way interaction with country. The model examining cessation among those who made a quit attempt found three significant two-way interactions with country. It is unclear if these observations are real or artefactual because the mechanism of action is unclear and we have no ready explanation. The general similarity of the findings across the four countries suggests that the relationships between these intrinsic measures and cessation are the essentially same and may be broadly generalisable to other countries with similar norms about smoking and personal characteristics.

The major strengths of this study include the large sample size of nationally representative samples of smokers and involvement of multiple countries. Limitations include the reliance on self-report cessation information, a relatively long follow-up time for cognitive predictors that can fluctuate notably over time, and the $25 \%$ attrition rate. This study also focused on individual-level predictors and thus is unable to shed light on possible effects of social and contextual variables. Forthcoming papers will focus on these important effects as experienced by our cohort members. ${ }^{46}$

In summary, nicotine dependence is the most important predictor of smoking cessation; it is also associated with making serious quit attempts, whereas motivational factors are only related to the likelihood of making a quit attempt.

\section{What this paper adds}

While there are several studies that examine basic intrinsic predictors of cessation, few utilise longitudinal data from nationally representative samples of smokers and even fewer that compare predictors of both cessation attempts and successful cessation across countries. Results from this study show that, in the four countries studied in this paper (Australia, Canada, the UK, and the USA), intention to quit and other cognitive variables were associated with quit attempts, but not cessation. Behavioural variables related to task difficulty, including measures of dependence, predicted both making attempts and their success. Predictors of making quit attempts and cessation were similar for each of the four countries, but there were some differences in predictors of success. The general similarity of results across countries suggests that these results are generalisable to other developed nations.

Few country-specific differences were observed, which suggests the observed predictors may generalise to other similar countries. Efforts to increase cessation rates should aim to increase the proportion of the population attempting to quit and should encourage the use of proven interventions for cessation.

\section{ACKNOWLEDGEMENTS}

The research was funded by grants from the US National Cancer Institute/NIH (from the Roswell Park Transdisciplinary Tobacco Use Research Center (TTURC), P50 CAl11236, and from R01 CA100362), the Canadian Institutes for Health Research (57897), Robert Wood Johnson Foundation (045734), the Australian National Health and Medical Research Council (265903), the Australian Commonwealth Department of Health and Aging, Cancer Research UK (C312/A3726), the Centre for Behavioural Research and Program Evaluation of the National Cancer Institute of Canada/Canadian Cancer Society, and the Canadian Tobacco Control Research Initiative.

\section{Authors' affiliations}

A Hyland, Q Li, R J O'Connor, K M Cummings, Department of Health Behavior, Roswell Park Cancer Institute, Buffalo, New York, USA R Borland, H-H Yong, Cancer Control Research Institute, The Cancer Council Victoria, Carlton, Victoria, Australia

A McNeill, Department of Epidemiology and Public Health, University College London, London, UK

G T Fong, Department of Psychology, University of Waterloo, Waterloo, Ontario, Canada

Conflicts of interest: none declared

\section{REFERENCES}

1 Corrao M, Guindon G, Cokkinides V, et al. Building the evidence base for global tobacco control. Bull World Health Organ 2000;78:884-90.

2 Centers for Disease Control and Prevention. Smoking prevalence among U.S. adults. http://www.cdc.gov/tobacco/research_data/adults_prev/ prevali.htm. (Accessed 12 March 2005).

3 Gilmore J. Report on Smoking in Canada 1985 to 2001. http:// www.statcan.ca/english/research/82F0077XIE/82F0077XIE2001001.pdf. (Accessed 12 March 2005).

4 White V, Hill D, Siahpush $M$, et al. How has the prevalence of cigarette smoking changed among Australian adults? Trends in smoking prevalence between 1980 and 2001. Tob Control Sep, 2003;12(suppl II):ii67-74.

5 Department of Health Statistical Bulletin. Statistics on smoking: England, 2003. http://www.dh.gov.uk/assetRoot/04/07/01/85/04070185.pdf. (Accessed 12 March 2005).

6 Jha P, Chaloupka F. Curbing the epidemic: governments and the economics of tobacco control. Washington, DC: World Bank, 1999.

7 Abdullah AS, Husten CG. Promotion of smoking cessation in developing countries: a framework for urgent public health interventions. Thorax 2004;59:623-30.

8 Palmgreen P. Uses and gratifications: a theoretical perspective. In: Bostrom RN, ed. Communication Yearbook 8 (61-72). Beverly Hills, California: Sage Publications, 1984. 
9 Ajzen I. The theory of planned behavior. Organizational Behavior and Human Decision Processes 1991;50.

10 Armitage CJ, Conner M. Social cognition models and health behaviour: a structured review. Psychology \& Health 2000;15:173-89.

11 Nguyen MN, Beland F, Otis J. Is the intention to quit smoking influenced by other heart-healthy lifestyle habits in 30- to 60-year-old men? Addict Behav 1998;23:23-30.

12 Yong $\mathrm{HH}$, Borland R, Siahpush M. Quitting-related beliefs, intentions, and motivations of older smokers in four countries: findings from the International Tobacco Control Policy Evaluation Survey. Addict Behav 2005;30:777-88.

13 Yu DK, Wu KK, Abdullah AS, et al. Smoking cessation among Hong Kong Chinese smokers attending hospital as outpatients: impact of doctors' advice, successful quitting and intention to quit. Asia Pac J Public Health 2004; 16:115-20.

14 Borland R, Owen N, Hill D, et al. Predicting attempts and sustained cessation of smoking after the introduction of workplace smoking bans. Health Psychol $1991 ; 10: 336-42$

15 West R, McEwen A, Bolling K, et al. Smoking cessation and smoking patterns in the general population: a 1-year follow-up. Addiction $2001 ; 96: 891-902$

16 Dijkstra A, de Vries H, Bakker M. Pros and cons of quitting, self-efficacy, and the stages of change in smoking cessation. J Consult Clin Psychol 1996;64:758-63.

17 Hellman R, Cummings KM, Haughey BP, et al. Predictors of attempting and succeeding at smoking cessation. Health Educ Res 1991;6:77-86.

18 Venters MH, Kottke TE, Solberg LI, et al. Dependency, social factors, and the smoking cessation process: the doctors helping smokers study. Am J Prev Med 1990:6:185-93.

19 Zimmerman RS, Warheit GJ, Ulbrich PM, et al. The relationship between alcohol use and attempts and success at smoking cessation. Addict Behav 1990;15:197-207.

20 Vanasse A, Niyonsenga T, Courteau J. Smoking cessation within the context of family medicine: which smokers take action? Prev Med 2004;38:330-7.

21 Hatziandreu EJ, Pierce JP, Lefkopoulou $M$, et al. Quitting smoking in the United States in 1986. J Natl Cancer Inst Sep 5 1990;82:1402-6.

22 Tucker JS, Ellickson PL, Orlando M, et al. Predictors of attempted quitting and cessation among young adult smokers. Prev Med 2005;41:554-61.

23 Hyland A, Li Q, Bauer JE, et al. Predictors of cessation in a cohort of current and former smokers followed over 13 years. Nicotine Tob Res 2004;6(suppl 3):S363-9.

24 Siahpush $M$, Borland $R$, Scollo $M$. Factors associated with smoking cessation in a national sample of Australians. Nicotine Tob Res 2003;5:597-602.

25 Hymowitz N, Cummings KM, Hyland A, et al. Predictors of smoking cessation in a cohort of adult smokers followed for five years. Tob Control 1997;6/suppl 2):S57-62.

26 Lando $\mathrm{H}$, Hennrikus D, McCarty M, et al. Predictors of quitting in hospitalized smokers. Nicotine Tob Res 2003;5:215-22.

27 Osler M, Prescott E. Psychosocial, behavioural, and health determinants of successful smoking cessation: a longitudinal study of Danish adults. Tob Control 1998:7:262-7.

28 Coambs RB, Li S, Kozlowski LT. Age interacts with heaviness of smoking in predicting success in cessation of smoking. Am J Epidemiol 1992;135:240-6.
29 McWhorter WP, Boyd GM, Mattson ME. Predictors of quitting smoking: the NHANES I followup experience. J Clin Epidemiol 1990;43:1399-405.

30 Osler M, Prescott E, Godtfredsen N, et al. Gender and determinants of smoking cessation: a longitudinal study. Prev Med 1999;29:57-62.

31 Secker-Walker RH, Flynn BS, Solomon $\sqcup$, et al. Predictors of smoking behavior change 6 and 18 months after individual counseling during periodic health examinations. Prev Med 1990; 19:675-85.

32 Nides MA, Rakos RF, Gonzales D, et al. Predictors of initial smoking cessation and relapse through the first 2 years of the Lung Health Study. J Consult Clin Psychol 1995;63:60-9.

33 Broms U, Silventoinen K, Lahelma E, et al. Smoking cessation by socioeconomic status and marital status: the contribution of smoking behavior and family background. Nicotine Tob Res 2004;6:447-55.

34 Hymowitz N, Sexton M, Ockene J, et al. Baseline factors associated with smoking cessation and relapse. MRFIT Research Group. Prev Med 1991;20:590-601.

35 Honda K. Psychosocial correlates of smoking cessation among elderly eversmokers in the United States. Addict Behav 2005;30:375-81.

36 Pisinger C, Vestbo J, Borch-Johnsen K, et al. Smoking cessation intervention in a large randomised population-based study. The Inter99 study. Prev Med 2005;40:285-92

37 Zhu SH, Sun J, Billings SC, et al. Predictors of smoking cessation in U.S. adolescents. Am J Prev Med 1999; 16:202-7.

38 Fong GT, Cummings KH, Borland R, et al. The conceptual framework of the International Tobacco Control (ITC) Policy Evaluation Project. Tob Control 2006; 15(suppl III):iii3-11.

39 ITC Four Country Survey Team. International Tobacco Control Policy Evaluation Survey (ITC 4-Country Survey) Wave 1 Technical Report. http:// arts. uwaterloo.ca/ itc/Downloads/ITC-W1-TechReportFinal.pdf. (Accessed 12 March 2005)

40 Thompson ME, Fong GT, Hammond D, et al. Methods of the International Tobacco Control (ITC) Four Country Survey. Tob Control 2006; 15(suppl III):iii12-18.

41 Heatherton TF, Kozlowski LT, Frecker RC, et al. Measuring the heaviness of smoking: using self-reported time to the first cigarette of the day and number of cigarettes smoked per day. Br J Addict 1989;84:791-9.

42 Hyland A, Levy DT, Rezaishiraz H, et al. Reduction in amount smoked predicts future cessation. Psychol Addict Behav 2005;19:221-5.

43 Hughes JR, Carpenter MJ. The feasibility of smoking reduction: an update. Addiction 2005; 100:1074-89

44 Carpenter MJ, Hughes JR, Solomon U, et al. Both smoking reduction with nicotine replacement therapy and motivational advice increase future cessation among smokers unmotivated to quit. J Consult Clin Psychol 2004;72:371-81.

45 US Department of Health and Human Services. Tobacco use among U.S. racial/ethnic minority groups: African Americans, American Indians and Alaska Natives, Asian Americans and Pacific Islanders, Hispanics. A report of the Surgeon General, 1998. Atlanta, Georgia: Centers for Disease Control and Prevention, Office on Smoking and Health, 1998. (US Government Printing Office Publication No S/N 017-001-00527-4.)

46 Hammond D, Fong GT, Zanna MP, et al. Tobacco denormalization, antiindustry beliefs, and cessation among smokers from four countries: findings from the ITC Four Country Survey. Am J Prev Med (in press) 